\title{
Failure Strength of Nonlinearly Elastic Composite Laminates Containing a Pin Loaded Hole
}

\author{
FU-Kuo ChANG AND RICHARD A. SCOTT \\ Department of Mechanical Engineering and Applied Mechanics \\ The University of Michigan, Ann Arbor, Michigan 48109
}

GEORGE S. SPRINGER

Department of Aeronautics and Astronautics

Stanford University, Stanford, California 94305

(Received February 22, 1984)

(Revised May 7, 1984)

\begin{abstract}
A method is presented for calculating the failure strengths and failure modes of composite laminates containing a pin loaded hole for materials exhibiting nonlinearly elastic behavior. The analysis follows that proposed by Chang, Scott, and Springer for linearly elastic composites with two notable exceptions: a) the shear stress-shear strain relation in each ply is taken to be nonlinear with the form proposed by Hahn and Tsai, and b) the Yamada-Sun failure criterion is modified to include nonlinear effects. Numerical results, generated using a nonlinear finite element scheme, were compared to data. These comparisons show that for laminates exhibiting nonlinear behavior the present analysis provides the failure strengths and failure modes more accurately than the previous method employing a linear stress-strain analysis.
\end{abstract}

\section{INTRODUCTION}

QEVERAL ANALYSES HAVE BEEN PROPOSED RECENTLY FOR CALCULATING the failure strengths and failure modes of composite laminates containing pin loaded holes [1-15]. All these analyses were formulated on the basis of linearly elastic material behavior. Indeed, it has been found [1-6] that the analyses using linear stress-strain relations provide reasonable results for laminates containing pin loaded holes except for ply orientations $[ \pm 45]_{\mathrm{S}}$ and $[0 / 90]_{s}$, where differences up to $40 \%$ were noted. The discrepancies were felt to be due to the fact that these laminates have strongly nonlinear elastic behavior, which the previous analytical models did not take into account.

Nonlinear behavior of laminated composites has been observed in experiments and is known to be strongly dependent on laminate ply orientation, 
loading direction, and environmental conditions. The primary cause of the laminate nonlinearity was found to be mostly due to the ply shear stresses once they became comparable to longitudinal tensile stresses [16-21]. The nonlinear material behavior becomes especially significant for notched laminates and, correspondingly, for laminates containing loaded holes. For this reason, the problem of nonlinear material behavior is addressed in this paper. In particular, an analysis is presented for calculating the failure strengths and failure modes of composite laminates containing pin loaded holes when the material exhibits nonlinear elastic behavior. The proposed analytical procedure is illustrated through its application to composite laminates containing a single pin loaded hole. However, the procedure is general, and can readily be extended to composites with two or more holes by combining the present method with that given in References [1-4].

\section{PROBLEM STATEMENT}

Consider a plate (length $\mathrm{L}$, width $\mathrm{W}$, thickness $\mathrm{H}$ ) made of $\mathrm{N}$ fiber-reinforced unidirectional plies. The ply orientation is arbitrary, but must be symmetrical with respect to the $x_{3}=0$ plane. Perfect bonding between each ply is assumed. A single hole of diameter D is located along the centerline of the plate. A rigid pin is inserted into the hole (see Figure 1). A uniformed tensile load $\mathrm{P}$ is applied to the lower edge of the plate. It is desired to find:

1) the maximum (failure) load $\left(\mathrm{P}_{\mathrm{M}}\right)$ that can be applied before the joint fails, and

2) the mode of failure.

\section{ANALYSIS}

The analysis follows the procedure given in References [1-4] for composites with linearly elastic material behavior. Accordingly, the analysis consists of four major parts
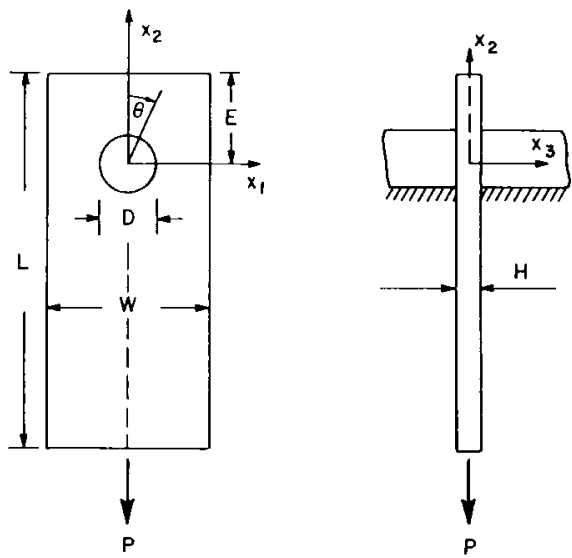

Figure 1. Geometry of the problem. 
1) formulation of the stress-strain relationships

2) formulation of the failure criterion

3) formulation of a failure hypothesis

4) stress analysis

Below, those concepts and procedures are emphasized which are different from those documented previously [1-4]. Details of the linearly elastic analysis [1-4] are not given except when needed to understand the present analysis.

\subsection{Nonlinear Shear Stress-Shear Strain Relation}

When a material exhibits nonlinear behavior, nonlinearities between shear stresses and shear strains are more important than nonlinearities between normal stresses and normal strains. Therefore, only the shear stress-shear strain relation is considered to be nonlinear in this investigation. The in plane stressstrain relations in each ply can then be expressed as

$$
\begin{gathered}
\left\{\begin{array}{l}
\sigma_{x} \\
\sigma_{y}
\end{array}\right\}=\left(\begin{array}{ll}
Q_{x x} & Q_{x y} \\
Q_{x y} & Q_{y y}
\end{array}\right)\left\{\begin{array}{l}
\varepsilon_{x} \\
\varepsilon_{y}
\end{array}\right\} \\
\sigma_{x y}=f\left(\gamma_{x y}\right), \text { or } \gamma_{x y}=f^{-1}\left(\sigma_{x y}\right)
\end{gathered}
$$

where $x$ and $y$ are coordinates parallel and normal to the fibers, respectively, and $[Q]$ is the reduced stiffness matrix $[4,25]$. The function $f$ is a relationship between the shear stress and the shear strain. Different investigators suggested different functions for $f[16-17,19-21,26]$. Here, the nonlinear shear stress-shear strain relation advanced by Hahn and Tsai $[16,17]$ is chosen. Accordingly, the shear stress-shear strain relationship is written as

$$
\gamma_{x y}=\left(1 / G_{x y}\right) \sigma_{x y}+\alpha \sigma_{x y}^{3}
$$

where $G_{x y}$ is the initial ply shear modulus and $\alpha$ is a constant that has to be determined experimentally. The tangent shear modulus, defined as the slope of the shear stress versus shear strain at each current position is

$$
T G=\frac{d \sigma_{x y}}{d \gamma_{x y}}=\frac{1}{1 / G_{x y}+3 \alpha \sigma_{x y}^{2}}
$$

\subsection{Failure Criterion}

The Yamada-Sun failure criterion has been successfully utilized in the analysis of linearly elastic composites with pin loaded holes [1-6]. This criterion is [27].

$$
\left(\frac{o_{x}}{X}\right)^{2} \quad\left(\frac{\sigma_{x y}}{S}\right)^{2}=e^{2} \quad \begin{aligned}
& e \geqslant 1 \text { failure } \\
& e<1 \text { non-failure }
\end{aligned}
$$


where $X$ is either the longitudinal tensile strength of a ply (if $\sigma_{x}$ is in tension) or the longitudinal compressive strength (if $\sigma_{x}$ is compression). $S$ is the actual ply shear strength for the laminate.

As was noted, nonlinear shear stress-strain relation is important in determining the failure strength and the failure mode of certain types of pinloaded laminates. It is felt that failure of these laminates cannot be predicted appropriately by only evaluating the current stresses, without regard to the history of the shear deformation. Therefore, when such nonlinearities are important the history of the shear deformation has to be taken into account in the failure criterion. To accomplish this, the Yamada-Sun failure criterion, based on only current stresses, is modified by incorporating Sandhu's strain energy failure criterion [18,19]. As will be shown below, the modified criterion can be applied when the material behaves in both a linear and a nonlinear elastic manner. The modified failure criterion is thus expressed as

$$
\left(\frac{o_{x}}{X}\right)^{2}+\frac{\int_{0}^{\gamma_{x y}} \sigma_{x y} d \gamma_{x y}}{\int_{0}^{\gamma_{x y}^{u}} \sigma_{x y} d \gamma_{x y}}=e^{2} \quad \begin{aligned}
& e \geqslant 1 \text { failure } \\
& e<1 \text { non-failure }
\end{aligned}
$$

where $\gamma_{x y}^{u}$ is the ultimate failure shear strain in a ply.

Note that the modified criterion reduces to Yamada-Sun failure criterion [27] if the shear stress-strain relation is linear. Equations (3) and (6) give

$$
\left(\frac{\sigma_{x}}{X}\right)^{2}+\frac{\frac{\sigma_{x y}^{2}}{2 G_{x y}}+\frac{3}{4} \alpha \sigma_{x y}^{4}}{\frac{S^{2}}{2 G_{x y}}+\frac{3}{4} \alpha S^{4}}=e^{2} \quad \begin{aligned}
& e \geqslant 1 \text { failure } \\
& e<1 \text { non-failure }
\end{aligned}
$$

For linearly elastic material $\alpha=0$ and Equation (7) reduces to Equation (5).

\subsection{Failure Hypothesis-Characteristic Curve}

The same failure hypothesis is adopted here as was used for linearly elastic composites [1-5]. That is, failure occurs when, in any one of the plies, the combined stresses satisfy an appropriately-chosen failure criterion at any point on a characteristic curve. The characteristic curve (Figure 2) is specified by the expression

$$
r_{\mathrm{c}}(\theta)=D / 2+R_{\mathrm{t}}+\left(R_{c}-R_{\mathrm{t}}\right) \cos \theta
$$

The angle $\theta$, measured clockwise from the $x_{2}$ axis, may range in value from $-\pi / 2$ to $\pi / 2$. $R_{t}$ and $R_{c}$ are the characteristic lengths for tension and compression. These parameters must be determined experimentally, as is discussed in Reference [6]. 


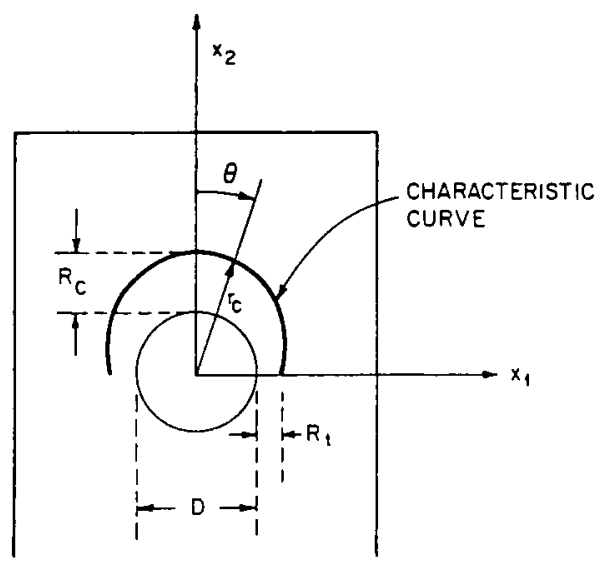

Figure 2. Description of the characteristic curve.

In this investigation, the characteristic curve is used together with the modified Yamada-Sun failure criterion. Accordingly, failure occurs when the parameter $e$ is equal to, or is greater than unity at any point on the characteristic curve

$$
\left.\begin{array}{l}
\text { No failure } e<1 \\
\text { Failure } e \geqslant 1
\end{array}\right\} \quad \text { at } r=r_{c}
$$

The location (angle $\theta_{f}$ ) at which $e$ first reaches the value of unity $(e=1)$ on the characteristic curve (Figure 2) provides an estimate of the mode of failure. Failure is taken to occur in the bearing mode when $\theta_{f}$ is small $\left(\theta_{f} \cong 0^{\circ}\right)$. Failure is taken to be due to shearout when $\theta_{f} \cong 45^{\circ}$. Failure is taken to be caused by tension when $\theta_{f} \cong 90^{\circ}$. In summary,

$$
\begin{array}{cl}
-15^{\circ} \leqslant \theta_{f} \leqslant 15^{\circ} & \text { bearing mode } \\
30^{\circ} \leqslant \theta_{f} \leqslant 60^{\circ} & \text { shearout mode } \\
75^{\circ} \leqslant \theta_{f} \leqslant 90^{\circ} & \text { tension mode }
\end{array}
$$

At intermediate values of $\theta_{f}$, failure may be caused by a combination of these modes.

\subsection{Stress Analysis}

In calculating the stresses in the laminate, the load is applied incrementally. In each step, a small incremental load $\Delta \mathbf{P}$ is applied until the failure load $P_{M}\left(=\Sigma_{k=1}^{n}(\Delta P)^{k}\right)$ is reached. It is assumed that the incremental load $\Delta P$ is so small that during each increment the shear stress varies linearly with shear strain and the deformations are small. The tangent shear modulus (the slope 
of the shear stress-shear strain curve) is calculated in each increment and the value thus obtained is used as the updated slope for the next step.

Based on these assumptions, the equilibrium equation in the absence of body force at the $n$-th increment can be written as

$$
\left[\Delta \sigma_{i j}\right]^{n}{ }_{j}=0 \quad i, j=1,2
$$

and the incremental stress-strain relations in the laminate are given by

$$
\left[\Delta \sigma_{i j}\right]^{n}=\left[E_{i j k}\right]^{n}\left[\Delta \varepsilon_{k}\right]^{n}
$$

where $\left[E_{i j k} J^{n}\right.$, the reduced moduli, are given by

$$
\left[E_{i j k l}\right]^{n}=\left[E_{r s}\right]^{n}=\sum_{p=1}^{N}\left(h^{p} / H\right)\left[\bar{Q}_{r s}^{p}\right]^{n}
$$

Here $h^{p}$ is the thickness of the p-th ply, and $\left[\bar{Q}_{r s}^{p} J^{n}\right.$ is the transformed reduced stiffness matrix for the p-th ply at the n-th increment [4,25], (see Appendix A).

The subscripts $i, j, k$ and $\ell$ are related to $r$ and $s$ as follows

$$
\begin{array}{llll}
i=j=1 & r=1 & k=\ell & s=1 \\
i=j=2 & r=2 & k=\ell & s=2 \\
i \neq j & r=3 & k=\ell & s=3
\end{array}
$$

Note that due to the updated shear modulus, the transformed reduced stiffness matrix $\left[\bar{Q}_{r s}^{p}\right]^{n}$ is not constant, and so the reduced moduli $\left[E_{m n}\right]^{n}$ depend on each increment. The incremental strains are related to the incremental displacements $\left[\Delta u_{j}\right]^{n}$ by the expressions

$$
\left[\Delta \varepsilon_{k}\right]^{n}=\frac{I}{2}\left(\frac{\partial\left[\Delta u_{k}\right]^{n}}{\partial x_{\ell}}+\frac{\partial\left[\Delta u_{\ell}\right]^{n}}{\partial x_{k}}\right)
$$

By multiplying Equation (11) by an arbitrary differential function $\Delta \bar{u}_{i}$, which satisfy the displacement boundary conditions, and by taking the volume integral over the laminate we obtain

$$
\iiint_{V_{o}}\left[\Delta \sigma_{i j}\right]_{, j}^{n} \Delta \bar{u}_{i} d V=0
$$

From this point on, the analysis follows the same line used in the case of linearly elastic composites [1-4]. On the basis of the arguments presented in References [1-4] a cosine normal load distribution is assumed to simulate the pin reaction force. Thus Equation (16) becomes 


$$
\begin{gathered}
\iiint_{V_{0}}\left[E_{i j k l}\right]^{n} \Delta \bar{u}_{i, j}\left[\Delta u_{k}\right]^{n}, l d V=\iint_{A_{L}}-(4 \Delta P / \pi D H) n_{i} \Delta \bar{u}_{i} \cos \theta d A \\
+\iint_{A_{R}\left[\Delta \sigma_{i j}\right]^{n} n_{j} \Delta \bar{u}_{i} d A}
\end{gathered}
$$

$V_{o}$ is the volume of the laminate. $A_{L}$ and $A_{R}$ are the boundaries where either load is applied or where displacements are restricted (Figure 3). $n_{i}$ is a unit vector normal to the boundary, pointing outward from the boundary surface.

The incremental displacements $\left[\Delta u_{k}\right]^{n}$ can be calculated by using a finite element method of solution. A suitable method of solution is described in References [1-4]. Once the incremental displacements $\left[\Delta u_{k}\right]^{n}$ are obtained, the incremental strains $\left[\Delta \varepsilon_{i j}\right]^{n}$ at the $n$-th increment can be calculated from Equation 15.

The incremental stresses at the $\mathrm{n}$-th increment, in the ply coordinate $x, y$ are given by

$$
\left\{\begin{array}{l}
\Delta \sigma_{x}^{p} \\
\Delta \sigma_{x}^{p} \\
\Delta \sigma_{x y}^{p}
\end{array}\right\}^{n}=[T]\left[\bar{Q}^{p}\right]^{n}\left\{\begin{array}{l}
\Delta \varepsilon_{1} \\
\Delta \varepsilon_{2} \\
\Delta \gamma_{12}
\end{array}\right\}^{n}
$$

The matrix $[T]$ is the coordinate transformation matrix [4,25]. The total strains and stresses at the n-th increment are given by

$$
\begin{aligned}
& {\left[\varepsilon_{i j}\right]^{n}=\sum_{k=1}^{n}\left[\Delta \varepsilon_{i j}\right]^{k}} \\
& {\left[\sigma_{x}\right]^{n}=\sum_{k=I}^{n}\left[\Delta \sigma_{x}\right]^{k}}
\end{aligned}
$$

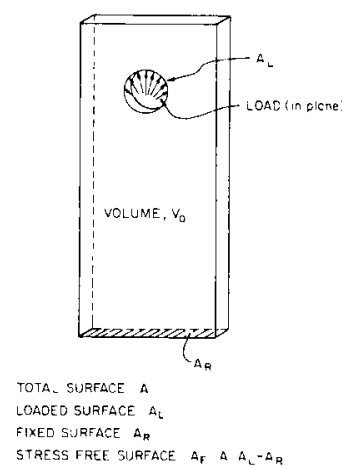

Figure 3. Configuration of laminate with a load hole. 


$$
\begin{gathered}
{\left[\sigma_{y}\right]^{n}=\sum_{k=1}^{n}\left[\Delta \sigma_{y}\right]^{k}} \\
{\left[\sigma_{x y}\right]^{n}=\sum_{k=1}^{n}\left[\Delta \sigma_{x y}\right]^{k}}
\end{gathered}
$$

The tangent shear modulus [TG] for the $n+1$ increment can be obtained by the approximation (see Equation 4).

$$
[T G]^{n+1} \approx \frac{\left[\Delta \sigma_{x y}\right]^{n}}{\left[\Delta \gamma_{x y}\right]^{n}} \approx \frac{1}{1 / G_{x y}+3 \alpha\left[\sigma_{x y}^{2}\right]^{n}}
$$

\section{SOLUTION PROCEDURE}

The numerical calculations to determine the failure load and failure mode of a composite containing a pin loaded hole are performed according to the following steps.

1) An incremental load $\Delta p$ is applied.

2) The components of incremental laminate strains $\Delta \varepsilon_{11}, \Delta \varepsilon_{22}, \Delta \varepsilon_{12}$ are calculated.

3) The incremental ply stresses $\Delta \sigma_{x}, \Delta \sigma_{x y}$ are calculated.

4) The total stresses $\sigma_{x}$ and $\sigma_{x y}$ are calculated.

5) The total applied load

$$
P=\sum_{k=1}^{n}[\Delta p]^{k}
$$

is calculated.

6) The modified Yamada-Sun failure criterion is applied in each ply along the characteristic curve.

a) If the failure condition ( $e \geqslant 1$ ) is satisfied at any point along the characteristic curve the iteration is terminated. The failure load $P_{M}(=P)$ and the failure mode are determined.

b) If the failure condition is not satisfied at any point along the characteristic curve then the calculations are continued.

7) The tangent shear modulus in each ply at each element is updated.

8) The procedure is repeated (return to Step 1).

A computer code (designated NLJOINT) was developed to perform the calculations. This code provides the failure strengths and failure modes of laminates containing a single pin loaded hole, with different ply orientations and different geometries. This code may be obtained from G. S. Springer. 


\section{RESULTS}

In order to evaluate the accuracy of the model, results generated by the model were compared to data. Data obtained previously with Fiberite T300/1034-C graphite-epoxy laminates were used in these comparisons. The experimental apparatus and procedures used in the tests are given in References [3,4]. The measured failure strengths and failure modes of laminates having different geometries and different ply orientations are shown in Figures 4-6. The ordinates in these figures represent the bearing strength $P_{B}=P / D H$, where $P$ is the failure load and $D H$ is the crosssectional area of the hole.

The bearing strengths and failure modes were also calculated using the model. The material properties listed in Table 1 were used in the calculations. All the properties in the table are from References $[3,4]$ except for the value of the constant $\alpha$. For lack of any other information, the value of $\alpha$ was taken to be the same as that measured by Hahn [17] for boron-epoxy composites.

The numerical results are included in Figures 4-6. The bearing strengths calculated by the previous "linear" model and the present "nonlinear" model

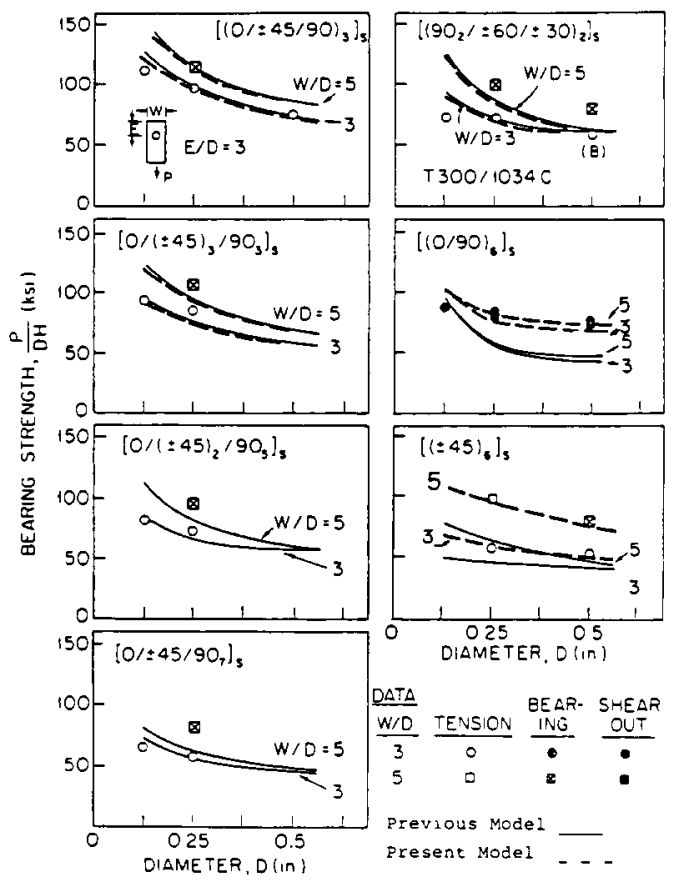

Figure 4. Bearing strengths of Fiberite T300/1034 C laminates containing a single loaded hole. Comparisons between the data and the results of the previous linear model and the present nonlinear model. 


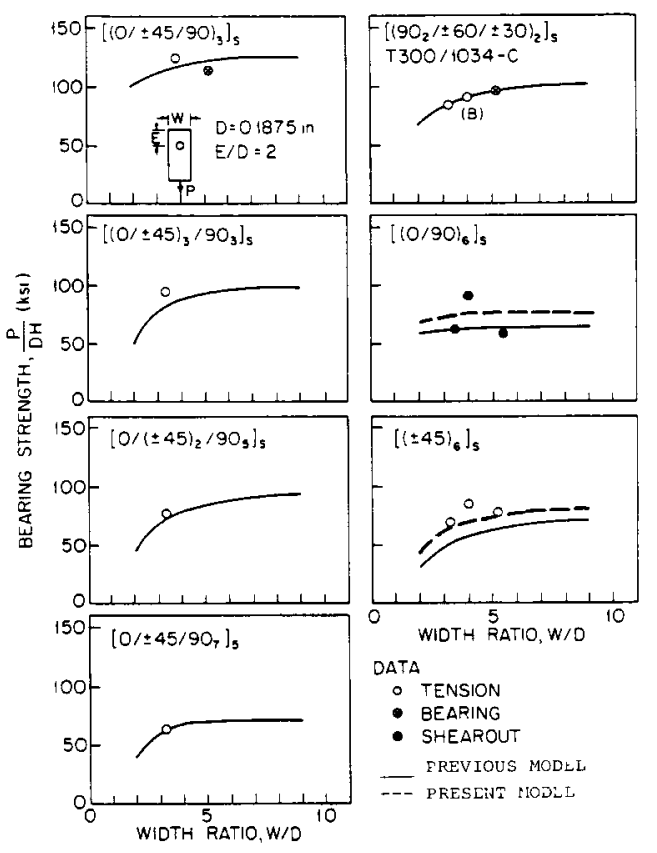

Figure 5. Bearing strengths of Fiberite $7300 / 1034 \mathrm{C}$ laminates containing a single loaded hole. Comparisons between the data and the results of the previous linear model and the present nonlinear model.

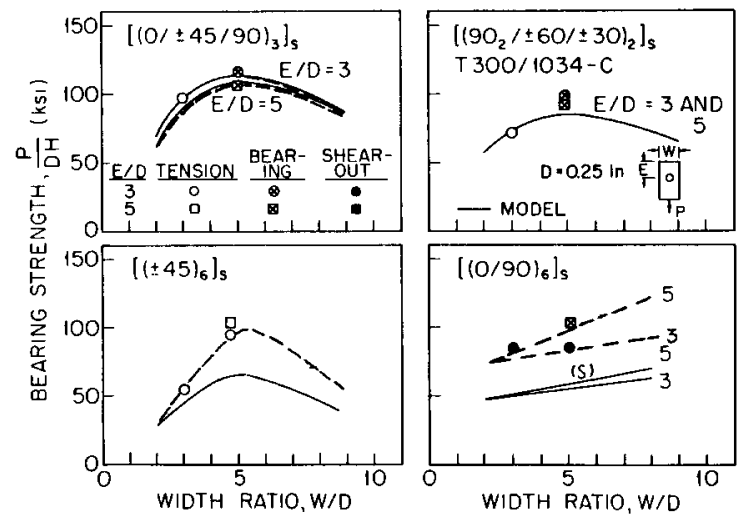

Figure 6. Bearing strengths of Fiberite $7300 / 1034 \mathrm{C}$ laminates containing a single loaded hole. Comparisons between the data and the results of the previous linear model and the present nonlinear model. 
Table 1. Properties of Fiberite T300/1034-C graphite/epoxy composite.

\begin{tabular}{llc}
\hline Longitudinal Young's modulus, $E_{x}$ & $=21300000 \mathrm{psi}$ \\
Transverse Young's modulus, $E_{y}$ & $=1700000 \mathrm{psi}$ \\
Shear Modulus, $G_{x y}$ & $=897000 \mathrm{psi}$ \\
Poisson's Ratio $\mu_{x y}$ & $=0.3$ \\
Longitudinal tensile strength, $X_{t}$ & $=251000 \mathrm{psi}$ \\
Longitudinal compressive strength, $X_{c}$ & $=200000 \mathrm{psi}$ \\
Rail shear strength, $S$ & $=19400 \mathrm{psi}$ \\
Characteristic length in tension, $\mathrm{R}_{\mathrm{t}}$ & $=0.018 \mathrm{in}$ \\
Characteristic length in compression, $\mathrm{R}_{\mathrm{c}}$ & $=0.07 \mathrm{in}$ \\
\hline
\end{tabular}

are indicated by solid lines and dashed lines, respectively.* The calculated failure modes were not identified separately as long as they were the same as those given by the data. In those cases where the calculated failure mode differed from the data, the calculated failure mode was identified by the letters $\mathrm{T}, \mathrm{B}$, or S, next to the corresponding data point. These letters represent failure in tension, bearing, and shearout modes.

As can be seen from Figures 4-6, for $\left[(0 / \pm 45 / 90)_{3}\right]_{s},\left[0 /( \pm 45)_{3} / 90_{3}\right]_{s}$, $\left[\left(0 /( \pm 45)_{2} / 90_{s}\right)\right]_{s},\left[\left(0 / \pm 45 / 90_{7}\right)\right]_{s}$, and $[ \pm 30 / \pm 60 / 90]_{s}$ laminates the bearing strengths calculated both by the previous "linear" and by the present "nonlinear" analyses agree with the data (as well as with each other). This result was expected in view of the fact that in these laminate coniigurations the ply tensile and compressive stresses (for which the stress-strain relations are linear) are much larger than the ply shear stresses. On the other hand, for $[0 / 90]_{\mathrm{s}}$ and $[ \pm 45]_{\mathrm{s}}$ laminates (in which ply shear stress dominated) the present "nonlinear" analysis predicts the bearing strength more accurately than the previous "linear" analysis. For these cross-ply laminates, the bearing strengths calculated by the present analysis agree with the data to within 10 to 25 percent. The bearing strengths calculated by previous analyses agree with the data only to within 10 to 40 percent.

The predicted modes of failure seem to be unaffected by the assumed stress-strain relation for the laminates exhibiting linear elastic behavior. For $[0 / 90]_{s}$ and $[ \pm 45]_{s}$ laminates, better predictions of failure mode were also found by the use of the present "nonlinear" analysis.

Finally, it is noted that the failure hypothesis-cheracteristic curve proposed previously [1-4] still remains a viable concept. More accurate results were achieved not by modifying the characteristic curve but by modifying the stress-strain relation.

\section{CONCLUDING REMARKS}

The model and corresponding computer code developed in this paper can be used to determine the failure strengths and failure mode of composite

*In cases where the linear and nonlinear results are indistinguishable, only a solid line is shown. 
laminates containing a pin loaded hole even when the material exhibits nonlinearly elastic behavior. Hence this model should enable the use of even those ply orientations which, because their unpredictable nonlinear behavior, designers were reluctant to use previously.

\section{ACKNOWLEDGEMENT}

This work was supported by the Mechanics and Surface Interactions Branch; Nonmetallic Materials Division, Materials Laboratory, Air Force Wright Aeronautical Laboratories, Wright-Patterson AFB, Ohio. Dr. S. W. Tsai was the project engineer.

\section{REFERENCES}

1. Chang, F.K., Scott, R.A., Springer, G.S., "Strength of Mechanically Fastened Composite Joints," J. of Composite Materials, Vol. 16, pp. 470-493 (1982).

2. Chang, F.K., Scott, R.A., Springer, G.S., "Strength of Mechanical Fastened Composite Joints," Air Force Wright Aeronautical Laboratories Technical Report AFWAL-7R-82-4095 (July 1982).

3. Chang, F.K., Scott, R.A., Springer, G.S., "Failure of Composite Laminates Containing Pin Loaded Holes-Method of Solution," J. of Composite Materials, Vol. 18, pp. 255-278 (1984).

4. Chang, F.K., Scott, R.A., Springer, G.S., "Strength of Bolted Joints in Laminated Composites," Air Force Wright Aeronautical Laboratories Technical Report AFWALTR-84-4029 (March 1984).

5. Chang, F.K., Scott, R.A., Springer, G.S., "Design of Composite Laminates Containing Pin Loaded Holes," J. of Composite Materials, Vol. 18, pp. 279-289 (1984).

6. Chang, F.K., Scott, R.A., Springer, G.S., "The Effect of Laminate Configuration on Characteristic Lengths and Rail Shear Strength," J. of Composite Materials, Vol. 18, pp. 290-296 (1984).

7. Waszczak, J.P., and Cruse, T.A., "Failure Mode and Strength Predictions of Anisotropic Bolt Bearing Specimens," J. of Composite Materials, Vol. 5, pp. 421-425 (1971).

8. Oplinger, D.W., and Gandhi, D.R., "Stresses in Mechanically Fastened Orthotropic Laminates," Proceedings of the 2nd Conference on Fibrous Composites in Flight Vehicle Design, pp. 813-834 (May 1974).

9. Oplinger, D.W., and Gandhi, D.R., "Analytical Studies of Structural Performance in Mechanically Fastened Fiber-Reinforced Plates," in Proceedings of the Army Syposium on Solid Mechanics, 1974: The Role of Mechanics in Design Structural Joints, Army Materials and Mechanics Research Center, AMMRC MS 74-8, pp. 211-242 (1974).

10. Agarwal, B.L., "Static Strength Prediction of Bolted Joint in Composite Material," $A L A A$ Journal, Vol. 18, pp. 1345-1375 (1980).

11. Soni, S.R., "Failure Analysis of Composite Laminates with a Fastened Hole," Joining of Composite Materials, ASTM STP 749, K.T. Kedward, Ed., Am. Soc. of Testing and Materials, pp. 145-164 (1981).

12. Garbo, S.P., and Ogonowski, J.M., "Effect of Variances and Manufacturing Tolerances on the Design Strength and Life of Mechanically Fastened Composite Joints," Flight Dynamics Laboratory, Air Force Wright Aeronautical Laboratories, Technical Report AFWALTR-81-3041 (April 1981).

13. York, J.L., Wilson, D.W., and Pipes, R.B., "Analysis of Tension Failure Mode in Composite Bolted Joints," J. of Reinforced Plastics and Composites, Vol. 1, pp. 141-153 (1982).

14. Wilson, D.W., and Pipes, R.B., "Analysis of the Shearout Failure Mode in Composite 
Bolted Joints," Proceedings of the 1st International Conference on Composite Structures, Paisley College of Technology, Scotland, pp. 34-49 (1981).

15. Collings, T.A., "On the Bearing Strengths of CFRP Laminates," Composites, Vol. 13, pp. 242-252 (1982).

16. Hahn, H.T., and Tsai, S.W., "Nonlinear Elastic Behavior of Unidirectional Composite Laminate," J. of Composite Materials, Vol. 7, pp. 102-110 (1973).

17. Hahn, H.T., "Nonlinear Behavior of Laminated Composites," J. of Composite Materials, Vol. 7, pp. 257-271 (1973).

18. Sandhu, R.S., “Nonlinear Response of Unidirectional and Angle-Ply Laminates," AIAA paper no. 74-380, presented at 15th AIAA-ASME Structural Dynamics and Materials Conference, Las Vegas, Nevada (1974).

19. Sandhu, R.S., "Ultimate Strength Analysis of Symmetric Laminates," AFFDL-TR-73-137 (February 1974).

20. Amijima, S., and Adachi, T., "Nonlinear Stress-Strain Response of Laminated Composites," J. of Composite Materials, Vol. 13, pp. 206-218 (1979).

21. Sims, D.F., "In-Plane Shear-Strain Response of Unidirectional Composite Materials," J. of Composite Materials, Vol. 7, pp. 124-130 (1973).

22. Tsai, S.W., "Strength Characteristics of Composite Materials," NASA CR-224 (1965).

23. Rotem, A., and Hashin, Z., "Failure Modes of Angle Ply Laminates," J. of Composite Materials, Vol. 9, pp. 191-214 (1975).

24. Tsai, S.W., and Hahn, H.T., "Failure Analysis of Composite Materials," presented as a symposium at 1975 ASME Winter Annual Meeting, Houston, Texas (1975).

25. Jones, R.M., Mechanics of Composite Materials, Scripta Book Company, Washington, D.C. (1975).

26. Gareia, R., Weisshaar, T.A., and McWithney, R.R., "An Experimental and Analytical Investigation of the Rail Shear-Test Method as Applied to Composite Materials," Experimental Mechanics, Vol. 20, pp. 273-279 (1980).

27. Yamada, S.E., and Sun, C.T., "Analysis of Laminate Strength and its Distribution," J. of Composite Materials, Vol. 12, pp. 275-284 (1978).

\section{APPENDIX A}

\section{The Transformed Reduced Stiffness Matrix $\overline{\mathbf{Q}}_{\mathbf{l}}$}

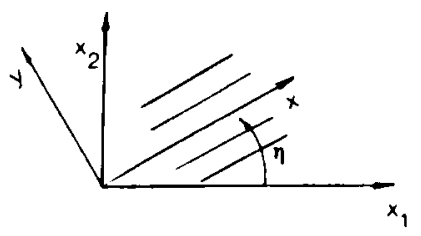

The components of the matrix $\bar{Q}^{p}{ }_{i j}$ appearing in (Equation 13) are

$$
\begin{aligned}
& {\left[\bar{Q}^{p}{ }_{11}\right]^{n}=Q^{p}{ }_{11} \cos ^{4} \eta+2\left(Q^{p}{ }_{12}+2\left[Q^{p}{ }_{33} J^{n}\right) \sin ^{2} \eta+Q^{p}{ }_{22} \sin ^{4} \eta\right.} \\
& {\left[\bar{Q}^{p}{ }_{12}\right]^{n}=\left(Q^{p}{ }_{11}+Q^{p}{ }_{22}-4\left[Q^{p}{ }_{33} J^{n}\right) \sin ^{2} \eta+Q^{p}{ }_{12}\left(\sin ^{4} \eta+\cos ^{4} \eta\right)\right.} \\
& {\left[\bar{Q}^{p}{ }_{22}\right]^{n}=Q^{p}{ }_{11} \sin ^{4} \eta+2\left(Q^{p}{ }_{12}+2\left[Q^{p}{ }_{33} J^{n}\right) \sin ^{2} \eta \cos ^{2} \eta \cos ^{4} \eta\right.}
\end{aligned}
$$


$\left.\overline{2}^{p}{ }_{13}\right]^{n}=\left(Q^{p}{ }_{11}-Q^{p}{ }_{12}-2\left[Q^{p_{33}}\right]^{n}\right) \sin \eta \cos ^{3} \eta+\left(Q^{p}{ }_{12}-Q^{p_{22}}+2\left[Q^{p}{ }_{33}\right]^{n}\right) \sin ^{3} \eta \cos ^{3} \eta$ $\left[\bar{Q}^{p_{33}}\right]^{n}=\left(Q^{p_{11}}+{Q^{p}}_{22}-2 Q^{p}{ }_{12}-2\left[Q^{p}{ }_{33}\right]^{n}\right) \sin ^{2} \eta \cos ^{2} \eta+\left[Q^{p_{33}}\right]^{n}\left(\sin ^{4} \eta+\cos ^{4} \eta\right)$ in which

$Q^{p}{ }_{11}=E_{x}^{p} /\left(1-\mu_{x p}^{p} \mu_{t x}^{p}\right)$

$Q^{p}{ }_{12}=\left(\mu_{x y}^{p} E_{y}^{p}\right) /\left(1-\mu_{x y}^{p}\right)=\mu_{y x}^{p} E_{x}^{p} /\left(1-\mu_{x y}^{p} \mu_{y x}^{p}\right)$

$Q^{p}{ }_{22}=E^{p}{ }_{y} /\left(I-\mu_{x y}^{p} \mu_{y x}^{p}\right)$

$\left[Q^{p}{ }_{33}\right]^{n}=\frac{1}{1 / G_{x y}+3 \alpha\left(\left[\sigma_{x y}\right]^{n}\right)^{2}}$

The superscript $p$ denotes the material properties of the p-th ply, and the angle $\eta$ is measured from the $x_{1}$-axis to the x-axis. $E_{x}^{p}, E^{p}$ and $G_{x y}^{p}$ are the longitudinal, transverse, and shear moduli of the p-th ply, respectively. $\mu_{x y}^{p}$ and $\mu^{p}{ }_{y x}$ are Poisson's ratios for the p-th ply and satisfy the relation

$$
\mu_{x y}^{p} / E_{x}^{p}=\mu_{y x}^{p} / E^{p}{ }_{y}
$$

$\left[o_{x y}\right]^{n}$ is the in-plane shear stress at the $\mathrm{n}$-th increment. 